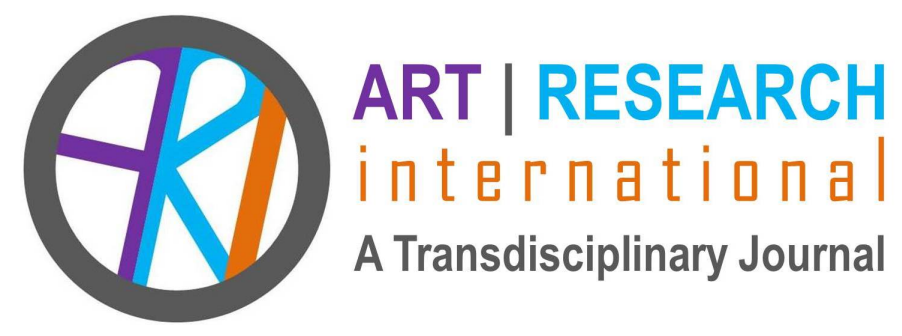

\title{
INTERWEAVING CONTEMPORARY ART AND "TRADITIONAL" CRAFTS IN ETHNOGRAPHIC RESEARCH
}

\section{Katerina Konstantinou Panteion University of Social and Political Sciences katerinikonstantinou@gmail.com}

\section{Aris Anagnostopoulos University of Kent, Heritage Management Organization a.anagnostopoulos@kent.ac.uk}

Katerina Konstantinou is a $\mathrm{PhD}$ candidate of Social Anthropology at Panteion University in Athens. She is an art historian and holds a Master's degree in Curating. Her research interests focus on the intersection of the fields of contemporary arts, anthropology, and heritage studies. Lately, she has been closely collaborating with artists in various projects that involve research methods and practices into the artmaking processes.

Aris Anagnostopoulos holds a PhD in Social Anthropology from the University of Kent. He has trained as a historian at the University of Leicester. His post-doctoral work is in the interdisciplinary field of archaeological ethnography. His research interests focus on the politics and poetics of the material aspects of the past in the present; he has also published extensively on the creation of public space in early $20^{\text {th }}$ century Crete. He has conducted ethnographic fieldwork with several archaeological projects, including the Kalaureia Project in Poros, Greece, and Koutroulou Magoula at Neo Monastiri, Fthiotida, Greece. He has been the director and principal instructor of the Archaeological Ethnography Summer School in Gonies, Crete since 2014. He currently works as a public programs director with the Heritage Management Organization, holds a Honorary Lectureship at the University of Kent, and is teaching at the Heritage 
Management MA (Kent \& AUEB) in Elefsina as well as the Anthropological Research Laboratory at Panteion University, Athens.

Abstract: This article presents a fieldwork collaboration between contemporary art, "traditional" craft, and ethnographic research in which community engagement plays a key role. Two decades after the abandonment of weaving in a depopulated mountainous village of Crete, Greece, a group of researchers invite an artist to turn the village's old school into a weaving studio. Aiming at the active participation of the local community in weaving heritage interpretation, and the interdisciplinary collaboration of art and anthropology, the weaving studio experience provides a fertile ground for discussing the relationships between disciplines, the difficulties of crossing the boundaries of these disciplines and the challenges of community participation in managing knowledge production. Here we discuss our experience working with an artist in a project between art and research, including various observations, different approaches, and challenges.

Keywords: community engagement; participatory ethnographic method; art-based methods; artistic research; cultural heritage engagement 
Collaboration between artists and anthropologists in an ethnographic fieldwork setting may look to both as an opportunity to further notions and practices of engagement and creative work. What brings artistic and anthropological concerns together in this case, is a recent turn in both fields towards practices that engage communities more in controlling and shaping research and creation. For art practice, this means further commitment to thinking and intervening in social formations, creating socially meaningful art that can transform lifeworlds (Sansi, 2015, p. 2). For anthropology, it means shifting the aims of inquiry from "descriptive": producing articles and monographs with restricted specialist readership; to "social" and "political": working together with people with an aim to challenge existing social relationships.

Such collaborations, however, precisely because they happen in the field, and not in a secluded studio, may also challenge the fundamental assumptions of both artists and anthropologists. The insistence of the former in creating a finished product and curating an audience for it may collide with the desire of the latter to keep their work open and make themselves accountable to what they perceive as the local community. Conversely, the reluctance of anthropologists to intervene in the field may rub against artistic freedom of expression and desire to experiment in ways that may produce social tensions.

In the case presented below, a community art project was woven into an already existing ethnographic archaeological fieldwork project with a rural community at a mountain village in Crete, Greece. This has resulted in a fertile, yet sometimes difficult, collaboration between art and anthropology. We aimed to put arts-based methods of fieldwork in practice, through hybrid interventions both in ethnographic research and in the daily life of the village. We invited Alexia Karavela, a visual artist based in Athens to join the team of anthropologists, archaeologists, and museologists for the duration of the annual archaeological ethnography summer school in July 2016. The initial idea was to set up a weaving workshop in the village, in order to engage locals in creating ethnographic knowledge and artistic content. The result was an open social space, in which many different groups discovered and performed different motives, aims, and expectations, framed within embodied memories, customs, and socially created perceptions of art and culture - even "traditional" culture at that.

While this research team has had quite some experience of putting artistic workshops into practice, this particular collaboration raised pressing questions about the ways in which anthropology engages with art and, conversely, the ways artistic practices are involved in the field of knowledge production. Our emphasis on creating ethnographic installations that act as zones of engagement is the theoretical horizon 
through which we approach art research, as explained below. This emphasis shifts our attention to process, rather than final outcomes, and therefore may initiate unexpected clashes with the expectations of production of an established art scene, on a national or international level. In what follows, we address some of these issues and questions by putting them in context in the field where they developed, so that clashes and convergences will be more specifically understood. Our ultimate aim, however, is to gravitate towards the collaboration between art and anthropology and the multiple ways artists and anthropologists could engage in fieldwork. Respectively, we consider the ways in which the field is recomposed through collaborative forms of research, not as discovery, but as communal knowledge production.

\section{The Broader Context of the Fieldwork in Gonies}

The Three Peak Sanctuaries of Central Crete project is an archaeological project led by Dr. Evangelos Kyriakidis, from the University of Kent, UK, that aims to investigate and publish the findings from past excavations in three peak sanctuaries in mountainous central Crete. Peak sanctuaries are places in top of mountains or hills in Crete, where ritual deposits of figurines and clay items were performed during Minoan times (c. 2500 B.C.). The ethnographic work undertaken from the beginning of the project initially sought to make the peak sanctuary of Filiorimos, above the village of Gonies, more relevant to the current inhabitants of the village. In time, however, and through consultation with the locals, its focus turned towards more recent heritage, history, memory, and the social processes that gradually depopulated the village from the middle of the twentieth century onwards (Kyriakidis \& Anagnostopoulos, 2015, 2017, and forthcoming). The project has aimed to facilitate the collaborative creation of placespecific knowledge that is effectively controlled by the community itself - even when this means that the initial focus of research has to be shifted to suit the interests of the community. We have therefore been experimenting with various new modes of presenting this ethnographic and heritage work to the local community and to the general public (Anagnostopoulos, Stefanou, \& Kyriakidis, 2017).

The current permanent population of the village of Crete is a mere 150, mostly elderly, people. Its older inhabitants remember a time when the village was almost a thousand souls strong, in the decade following the Second World War. The village is full of empty houses which are slowly turning into ruins. For its inhabitants, it is a landscape of abandonment, filled with the memories of neighbors now long deceased or migrated to cities of the world. While our work and community engagements took place mostly in the village, the extent of the village diaspora in the nearby city of Heraklion and worldwide and the control it exerts over social media, web, or other public content, has made us aware that the public we are addressing is not just the localized, small 
community of mostly elderly people that is the village today, but a globally extended network of stakeholders that have a voice and are intent on controlling the representations of their village of origin (Kyriakidis \& Anagnostopoulos, 2017). Our use of the concept "community" is heuristic and refers to these different levels of participation.

From the beginning of our engagement in the village the most pressing demand set by locals was to employ our archaeological and heritage work to "bring people back to the village." The goal of community regeneration was set very vocally, but we aimed to avoid processes that "authorised" local heritage and inscribed it into officially approved forms. Instead, we opted for participatory methods that would enable the village community to decide for itself the course of the project, as well as take it up on itself to build sustainable forms of heritage management. In this decision, we aimed to avoid "mainstreaming" the heritage of the village, and instead focus on the processes that make community engagement possible. This is a rationale that aims to shift the focus from exhibitions and museum projects that turn the living memory of the past into parochial spaces or folkloristic narratives towards open-ended, performative activities that encourage participation.

....we see artistic projects as events in themselves, as

Participatory exercises that invite artists to conduct ethnographic research in various imaginative and creative ways (Culhane \& Elliott, 2017) have seen a considerable growth lately and so has the scholarly literature (Grimshaw \& opportunities for the creation of such knowledge that cannot be transmitted by talking.. . Ravetz 2005; Schneider \& Wright 2006, 2010, 2013; Laine, 2018). Participatory art projects are a mainstay of the methods we put into practice in the field with a number of considerations in mind. First, we see participatory art projects as a method of giving back to the people the information they have volunteered to our research, in a way that makes this knowledge open to interpretation, negation, comment, and criticism. Second, we see artistic projects as events in themselves, as opportunities for the creation of such knowledge that cannot be transmitted by talking but instead evoked by the presence of people in the field. We see participatory projects as an opportunity to manage knowledge differently, by inviting locals to be teachers of their own heritage and engage in its recording, preservation, and dissemination. In this respect, we have also set up an annual field school that coincides with our field research every summer. Students from all over the world participate in our research, and are instructed in the methods of field research and the issues involved in setting up a community engagement program. 
In this context, in July 2016 we put into practice an experimental way of doing fieldwork by involving locals in an open artist studio. The artist Alexia Karavela set up a weaving workshop in one of the large halls of the disused primary school of the village. We intended this experimental merging of contemporary art and ethnography as an "ethnographic installation," a setup situation evocative of embodied memories and setting up the communal creation of knowledge about the senses.

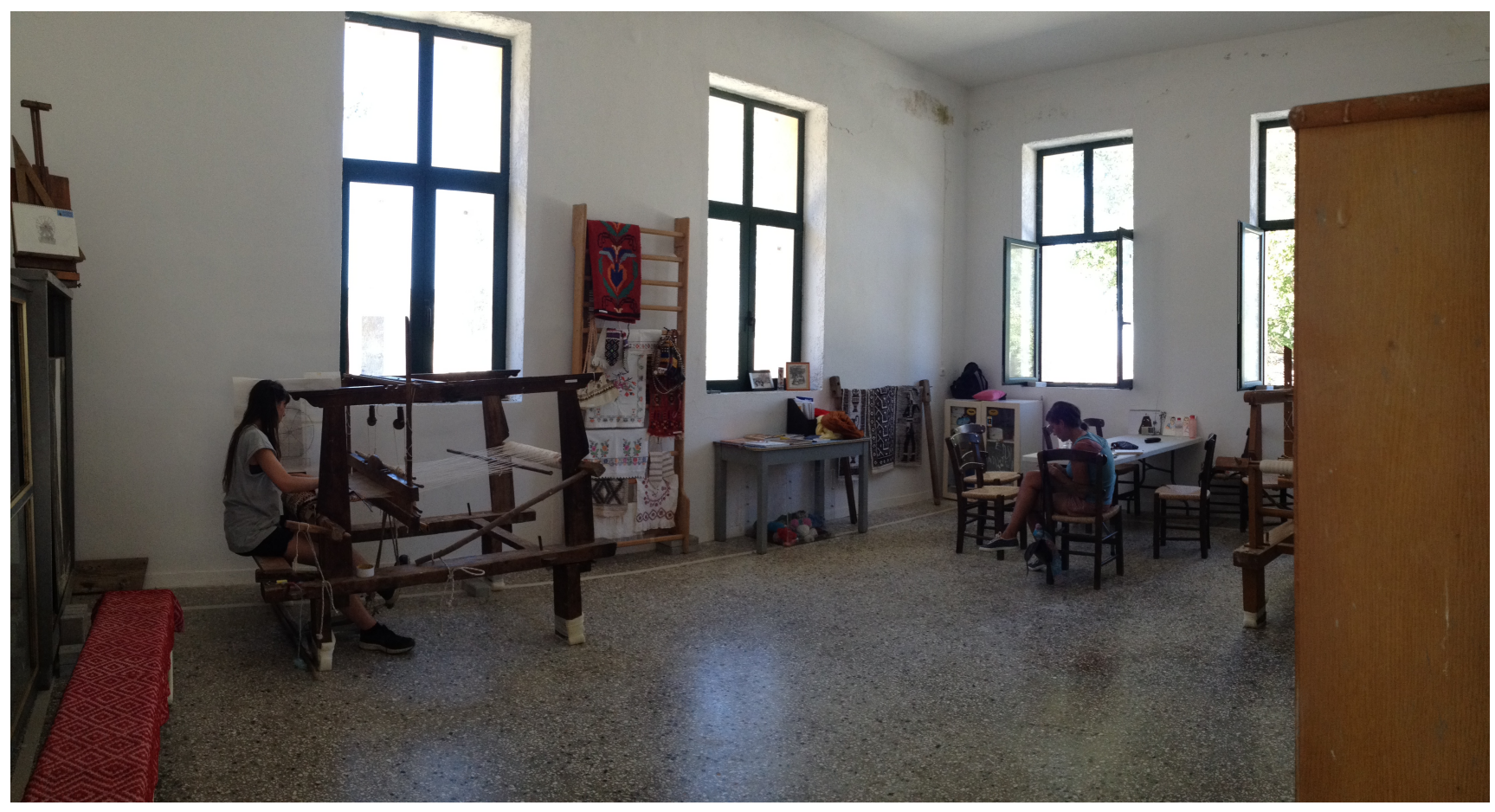

Figure 1. A view of the weaving studio. Photo credit: Katerina Konstantinou

\section{Ethnographic Staging, Performativity, and the Concept of Ethnographic Installation}

Castañeda (2009) introduces the notion of ethnographic installation by stating that this is an action that on a first level looks like a "public outreach" activity - giving back to the subjects of fieldwork knowledge acquired from them in a different temporal setting, either by the researchers themselves or other knowledge-producing processes. However, the creation of an ethnographic installation involves a staging of ethnographic research itself. Most importantly, instead of the researcher, artist, or ethnographer imposing a specific meaning or narrative on the production of knowledge of the past, she chooses to make this past present in an open-ended way that facilitates its re- 
appropriation by members of the community that have a stake in this past (Castañeda, 2009, p. 266).

In the presentation of ethnographic and historical work in Gonies, while ethnographers are active in engaging members of the community to participate in research and presentation, the final product is not a unique narrative, but a "curating" of many different stories, objects, and places, that seeks to incorporate as many voices as possible in the final outcome. Even so, the outcome itself, be it a heritage trail of the village or an exhibition of material produced by the community, demands a coherent narrative, since it is also aimed at addressing people coming "from outside": visitors to the village, tourists, the interested public at large. Our experimenting with ethnographic installation introduces instead the process of an open studio where things happen, stories unfold, people meet and discuss, works are produced, and possibilities are created. The very process itself becomes the focus of the work, and not the finished product itself. The process is not, or not only, the evocation of a historical experience, a past "already there," but also a meeting ground between the embodied, sensuous knowledge of the past and our formal, social-scientific and historical methods of approaching it. The creation of an open art-studio, in this respect, also turns the ethnographic team itself into an object of study.

\section{Engagement Zones}

As a form of collaborative engagement, the open weaving studio was preconceived as a conceptual, physical, and temporal space in the way Onciul (2015) theorized "engagement zones" (p. 72). Although Onciul refers to museums and the recent museological turn towards multiple alternative narratives about the past, we find the conceptualization of engagement zones appropriate for the analysis of our research art studio which explored older weaving techniques but was not limited to these. The whole project bore characteristics of a temporary participatory performance or an openended exhibition. In this context, unpredictable interactions among expected and unexpected participants formed a complex and multifaceted temporary community within which anthropologists followed the lead of the artist and the locals. Thus the studio reinforced different narratives, stories, and recollections as well as impromptu activities held by locals in the reactivated space of the old school. This was made possible through a variety of engagement approaches, including generating debates concerning weaving or other issues, hosting feasts, and creative activities for kids. 


\section{Socially Engaged Art Research Methods}

In this project, apprenticeship was employed both as a field method and as a means of engagement with the Goniotes. As an ethnographic method, apprenticeship was introduced as an innovative method of research in the late 1980s (Coy, 1989). Many anthropologists have been apprenticed to practitioners, especially to study bodily arts (Downey, Dalidowicz, \& Mason, 2015). Although weaving is not a bodily art, it is a bodily technique and therefore it is difficult to learn by reading any sort of guidelines. Learning through observation and practice has been the common way of gaining the appropriate skills for weaving in Crete. In the last decades, applying such practices in fieldwork has moved beyond mere apprenticeship to more socially engaged methods, and this shift led to an increasing interest in arts-based research (Barone \& Eisner, 2012). The weaving studio in Gonies required the collaboration between the artist and the research team, as well as the participation of locals in the research process. The active involvement of these different participants drew attention to complex issues such as the uncertainty of anthropological interpretations and the contingency of research relations in the field. This flexible and participatory approach was enabled due to the open-ended nature of such artistic events that are equipped to respond to a whole range of needs and expectations. Arts-based research furthermore provides opportunities for surprise as it often generates uncertainties more than certainties (Wang, Coemans, Siegesmund, \& Hannes, 2017, p. 12) and challenges prevailing interpretations.

\section{Weaving in Gonies}

We conducted our planning for the weaving research project, built upon research on textile production in Gonies, in July, 2015. During this initial month-long stay, we focused on elderly women and their stories about weaving and about other handmade, embroidered, and crocheted textiles. Most of our visits to homes of elderly women ended up in a demonstration of woven artifacts - this is a common occurrence that serves as a means to forge social relationships in the village, but also has a practical aspect of exchanging new designs and ideas. The centrality of woven artifacts to the sociality and liveworlds of elderly women inspired us to further our research and engagement with weaving as a practice and an aesthetic implicated in forms of production and social reproduction, as well as much broader networks of power and exchange.

In Gonies, woven textiles originally catered to household needs but eventually became mass-produced touristic souvenirs after the growth of the Cretan tourist industry in the 1960s. Mass production altered the patterns, motifs, forms, and weaving 
techniques to meet the standards of the industry and cater for the expectations of tourists. A variety of ornamental textiles with themes that drew on the prevailing view of the ancient Minoan past of Crete gradually appeared. Specific textile motifs were commissioned from local weavers by wholesalers from mainland Greece, and these orders soon came to standardise a few motifs for mass production. For example, representational images such as the depiction of the "Prince of the Lilies," a fresco dated to circa 1550 B.C. that was found in Knossos, a Minoan Bronze Age archaeological site and a major attraction for tourists in Crete. In Gonies, "Prince of the Lilies" became a centrepiece of this new style of weaving, and is thought to represent King Minos, the legendary King of Knossos, who allegedly passed through the village on his mythical walk to the top of the mountain Psiloritis to meet his father, Zeus, and to renew his mandate.

The mixture of "ancient" motifs with the rural culture of weaving in mass textile production fit with the explicit aims of national tourist agencies and ministries: it was mostly intended to transmit the impression of cultural continuity from ancient to modern Greece to discerning tourists. Weaving techniques, such as the triopatitero, ${ }^{1}$ cloth motifs, and the detailed function of the loom itself have been documented in detail by "folk culture" studies of rural populations in Greece, which usually represented villagers as "domestic exotics" within the sovereign national state (Herzfeld, 1987, p. 10). While critical approaches have been developed within folklore studies in the recent years, the study of weaving (see for example Michelogiannaki-Karavelaki, 2015), as well as other aspects of village technical production, are still studied in an unreflexive manner. These approaches, in tandem with earlier touristic aesthetics of production, have shaped a dominant discourse that creates the "Cretan loom" as an object that is both evidence of cultural continuity and local exceptionality. The setup and use of the loom is traced back to ancient times, based on a variety of loom-weights found in several archaeological excavations all over Greece. Weaving practices are supposed to have continued without interruption from Minoan Crete to the 20th century. Nearer contemporary times, weaving was a predominantly female activity that contributed to the social reproduction of the household, either in the form of making cloth for everyday needs, or in preparation of a dowry for younger girls. The image of the young unmarried woman weaving her own dowry in preparation of her betrothal to the one she loves is a common theme in many old songs and local stories in Crete. In the context of the transformation of this reproductive activity to heritage selling point, the Cretan loom was promoted as an artifact with unique characteristics, despite the fact that there are no significant differences between the "Cretan loom" and the typical looms that exist all around Europe. 
The standardised "traditional" motifs that gradually replaced local production were however perceived differently by local weavers. For them, the colourful but inelegant wool textiles that were most desired by tourists were a continent away from the fine cotton textiles of the Goniote dowries that had been passed on from generation to generation. For about three decades in the middle of the last century, Goniote women were regularly commissioned to produce massive amounts of the bestselling textiles, which gradually replaced the more delicate cotton ones that lost both their everyday and social functions. During that period, both men and women contributed to textile production, but it was mostly women that invested countless hours in the loom. Modernization was thus a process associated with a shift in the aesthetic expectations of production and the social use of the artefacts produced, but at the same time the intensification of an already arduous manual task. Even as their manual work intensified, it remains unclear whether the changing role of women as producers improved their social standing in the village society. At the same time, the period of transformation of textile production coincided with a series of transformations on a larger scale, that brought about changes that are felt as ruptures in village life. In their narratives on weaving there was often a "before" and "after," mostly linked with phrases such as: "...and then tourism came along..."

Dominant folklore discourses, in their collusion with an expanding tourist trade, thus served to disguise the very process of production and the transformation of aesthetic practices through a variety of contemporary factors by presenting a romanticized, idealized image of village women, and village life in general. Opening up a performative space in Gonies alerted us to the plain facts of weaving that are never addressed in these romantic accounts. Weavers in Gonies describe weaving as a necessary evil, a physically exhausting chore, with long hours of repetitive movements of arms and legs while sitting on an uncomfortable wooden beam. The intensification of production meant even more onerous work for women, who were not relieved of their household chores. Women's memories of weaving are not the smooth, idealized discourses of youth and love that folklore praises, but narratives of poverty, hard work, and unfulfilled expectations.

Weaving served as an important source of income and was a primary occupation for the village along with livestock farming (Herzfeld, 1985). Almost every house owned a loom and women weaved "day and night," often in poorly lit and cramped rooms. ${ }^{2}$ Gonies never became a host for mass tourism as the rest of the island did after the tourist boom of the 1960s and 1970s. Weaving was perhaps the most significant way Goniotes were involved in tourism - besides the groups of itinerant stonemasons from the village who built several traditionally-themed bungalows in large-scale tourist units, especially in eastern Crete. Developments on the tourist market during the 1980s and 
1990s resulted in the abandonment of weaving. Low-cost, factory-made textiles made handmade textiles unprofitable and eventually looms fell into disuse. At the same time, woven textiles became old-fashioned and were gradually replaced by industrial fabrics.

The affective load of heritage in the village, especially in view of its depopulation and abandonment, turns to objects such as woven textiles as an anchor to a distant past that may not be remembered as a time of prosperity and good life but is approached with a deep nostalgia for a sense of community. While many looms have been purposefully destroyed, others have been preserved, along with many woven textiles. Although not in use, these textiles are much appreciated for being rare, old, handmade and, more importantly, family heirlooms. As heritage, both the looms and the remaining woven textiles of the village are regarded by some locals as important enough to be in a local museum that would both safeguard the memory of the community in precious material evidence of the past, and attract tourism in Gonies, as locals imagine it. Yet, the idea of building such a museum is dangerously similar to existing folklore museums throughout Greece, which are often criticized for being mere storage houses for haphazardly collected objects. Goniotes, as it was expressed by a local young man, would prefer a monothematic museum that would invite its audience to engage in activities through which knowledge about the past can be gained. This view of a museum is probably related to recent developments in museums that meet the demands for more engagement and involvement (Black, 2005).

Having in mind this local quest for an engaging museum exhibition along with a manifold of stories regarding weaving and the abundance of material remnants of this relatively recent past, setting up a space where people would gather around a functioning loom seemed in line with community expectations.

\section{A Reluctant Apprenticeship}

We invited the visual artist Alexia Karavela not only because her work is relevant to this research, but more importantly was due to her practices that could easily be applied to fieldwork, albeit with very different goals and expectations. Alexia engages with the recent past of Greece by re-reading and interpreting objects and found images in various unexpected ways - often as a critical comment on past realities. Focusing on how politics are expressed in the everyday, Alexia re-examines related fragments and associates them in meaningful, yet surprising ways. Alexia has developed a distinct way of painting with marker pens, through which she turns found old photographs into vibrantly colored paintings. Beyond her painting, she has also presented installations involving a variety of media such as weaving with unusual materials and assemblages of ready-made objects. 3 Therefore Alexia was invited to join the research team to set up 
and run the weaving studio in the abandoned school of Gonies. Her participation was planned as a month-long intervention both in the research project and the everyday life of the village, one that would help us think beyond the usual ethnographic practices employed in research settings.

The place chosen for the workshop was the village's school building, disused since the early 2000s for lack of pupils. The school was completely refurbished by the community during the last few years, in hopes of setting up a multipurpose building for the village. Until today, it acted mainly as a voting station for the national and regional elections, as storage facility for the religious celebration of the 15th of August and some rare wedding parties that are held in its yard during the summer season. This occasional operation of the school building revives hopes among locals for a social space that would accommodate some still undefined cultural activities that would attract visitors to Gonies. At the same time, there are no expectations of turning the building into a school again, as most of the younger Goniotes live in the nearby city of Heraklion.

One of the spacious halls of the school that remained in disuse for years was transformed into an artist's studio for the purposes of the "weaving project." Within the first week of our stay, and as we spread the news among the locals that we were looking for a loom, a young man who lives in Heraklion and was at that time renovating his old house in the village, offered his aunt's loom that had been kept in a cellar for decades. This wooden loom was dismantled and moved to the school. It took several days to make it functional, and this was made possible only after the intervention of two of the most experienced elderly weavers. While Alexia was already introduced to the local community as an apprentice, elderly weavers responded with some hesitation which is not unusual in apprenticing in fieldwork (see for example the case of Elayne Zorn (2004, p. 22) in the Andean island of Taquile). It was only after the first women who joined us in the school spread the word, that other weavers and non-weavers started visiting the studio.

For the rest of our stay in Gonies, the weaving studio was a place to engage in the process of creating knowledge (Pink, 2005) and was shared between both the locals and the anthropologists. The performative aspect of the presence of Alexia and the reenactment of the weaving experience created an environment, within which artistic practices coexisted with everyday life and scholarly methods. Shortly after the first loom started weaving, the school became a meeting point for three different groups of people: a group of elderly women that was gathered in the school primarily to teach us how to weave; a group of young men who were there to spend time with us; and the group of students who were attending the field school of Archaeological Ethnography (Anagnostopoulos et al., 2017, p. 95). The idea of making an easy, communally-woven rug brought all these groups together in a single endeavour. 


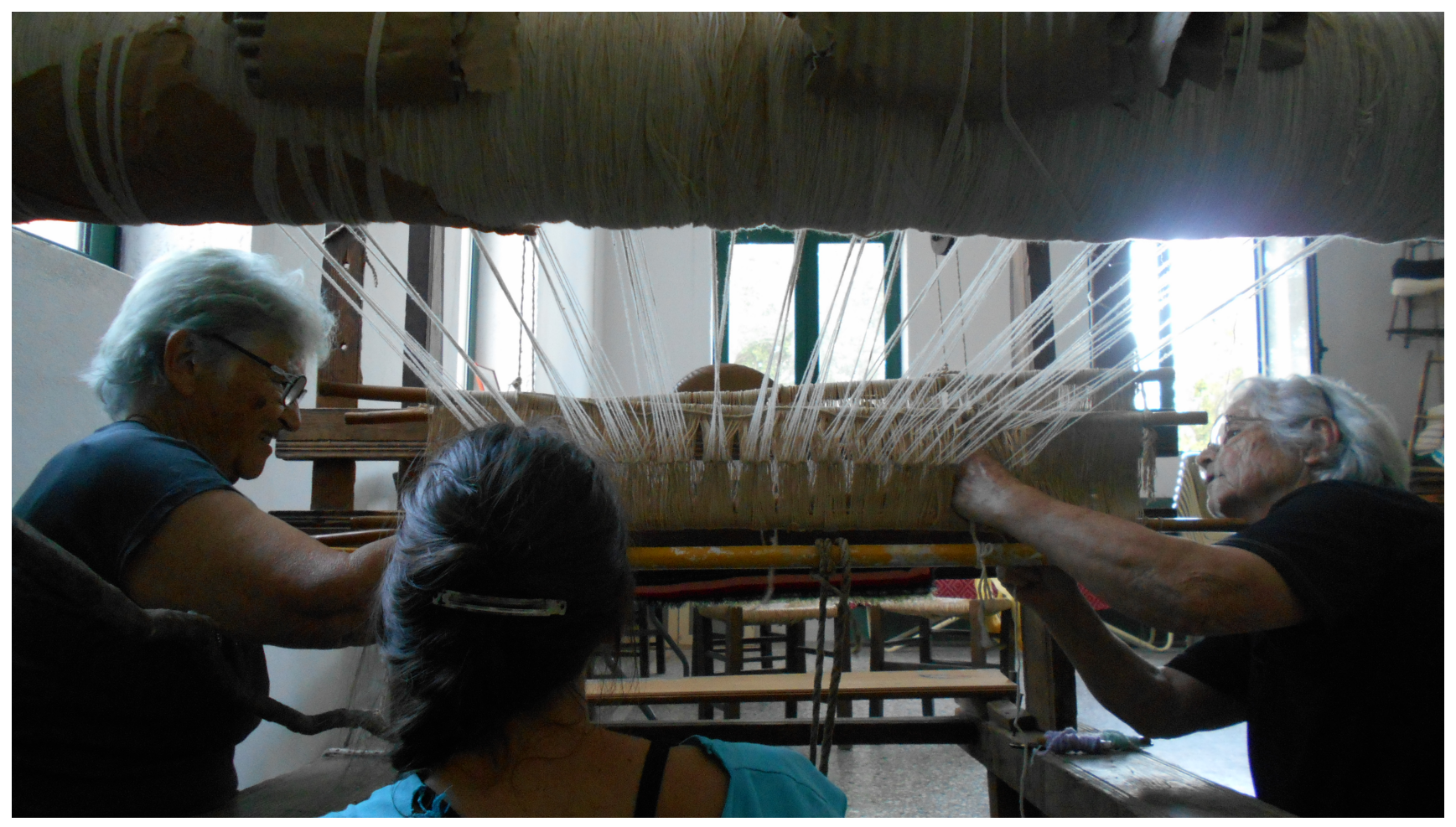

Figure 2. Local weavers and the artist assembling the loom. Photo credit: Katerina Konstantinou

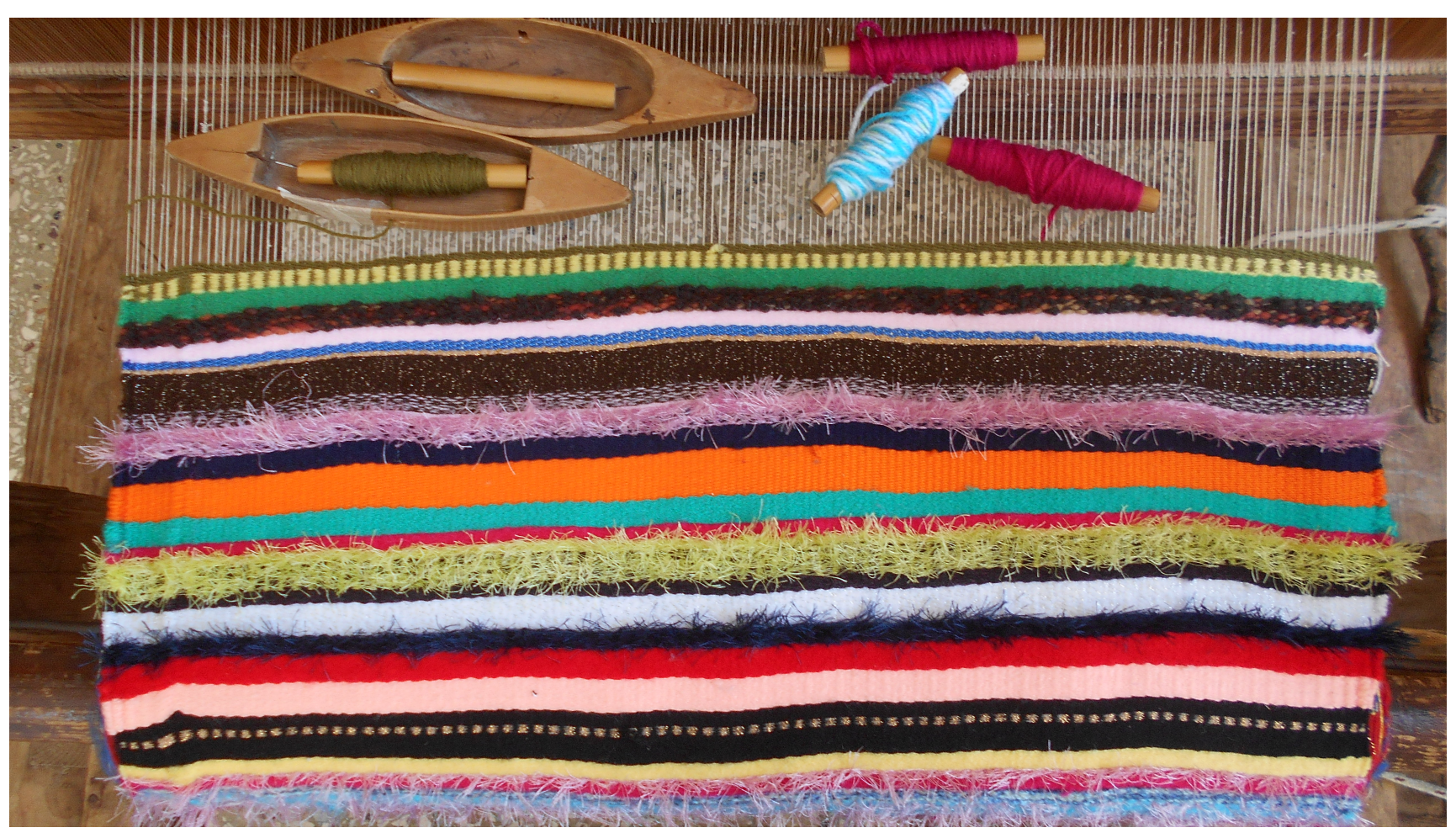

Figure 3. The communally woven rug. Photo credit: Katerina Konstantinou 
The close, everyday collaboration necessitated the need to combine different intentions and expectations of all involved. As more and more people got involved, it became apparent that the direction of the project was not entirely in our hands, and that different groups and individuals with different capacities and demands began to push it in different directions.

Elderly women, who were initially our main interest in this project, rarely appear in public, in the kafeneio or on other social occasions. They started visiting the studio in small groups with some hesitation but eventually took the leading role in the course of the workshop. They soon took the initiative to bring a second loom to the studio to demonstrate the production of a delicate fabric, decorated with floral and geometric patterns. The new loom, better made than the first, was easier to work and facilitated the complex technique of "triopatitero" (see Note 1).

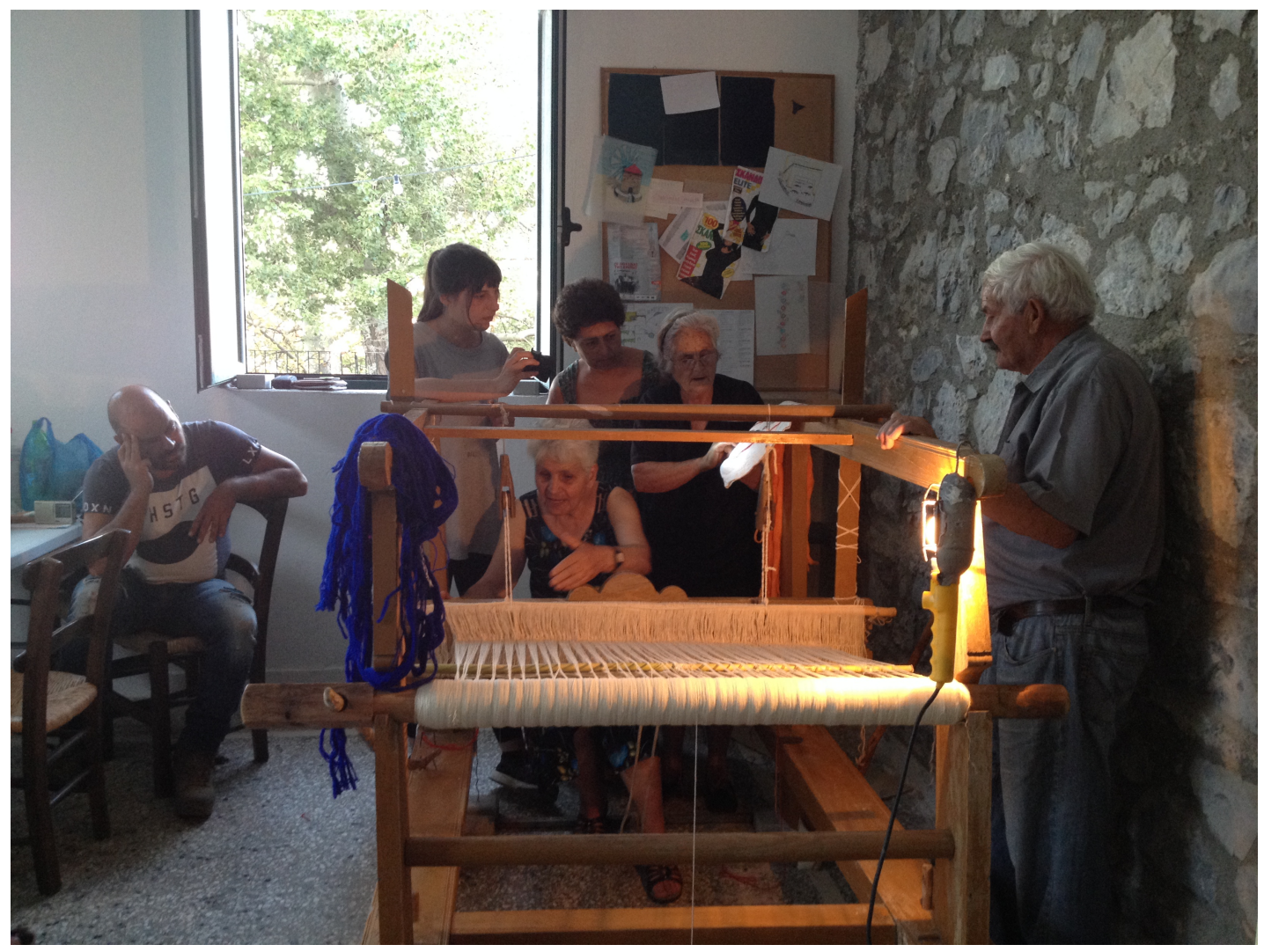

Figure 4. Weaving the triopatitero. Photo credit: Katerina Konstantinou

Once the second loom arrived in the studio, it became apparent that the experienced weavers were not very fond of our first loom. On a first level, we understood that the communally woven rug was not challenging enough for these experienced weavers. Gradually, we began to realise that their dislike was about more than just the challenge of weaving. Alexia, having herself experienced the taxing 
experience of long hours on the loom soon realised that all these years of working for the wholesalers must have created a difficult memory. This idea was further reinforced by the fact that some weavers recalled how they burned their abandoned looms.

Surprisingly, while we had been shown many textiles woven with skill and technical dexterity, we had still to encounter one of the textiles made for the mass market. We initially assumed that, since these were made on demand, there were none left in Gonies. It transpired that women were reluctant to show these artifacts, firstly because they considered them of little value, and also because they testified to this difficult memory of hardship and exploitation. It took some time to get to see a "Prince with the Lilies" made in kouskouse, the technique that was mostly used for touristic textiles. This rare item was preserved by its almost 80-year-old weaver because it was made with a "wrong" background color and therefore it was not "traditional" enough for the wholesalers. Two more representative artifacts came in soon afterwards. The one depicted the "Route of Love," a geometric pattern drawn from the ancient Minoan past, and the other one depicted a typical ancient vase ornamented with geometric patterns. This preference for the textiles they produced for themselves and their households was based not only on an aesthetic value but also on a presumed "authenticity." Souvenir textiles were standardised by wholesalers in a simplified "traditional" form in order to fit market needs. Moreover, they were consumed by tourists who visited Crete with their own "tourism imaginary" (Salazar, 2012) for the place and people, which aligned with the narrative of weaving as a continuous tradition that links the present to the ancient past.

The elderly women involved in the project overcame their initial reluctance and gradually began to shape the process to suit their needs and desires. The use of craft in this workshop made it a familiar space to them and gave them a sense of empowerment because they realized their position as instructors of a knowledge that only they themselves had. This knowledge could not be transmitted through other means besides bodily techniques of apprenticeship. This feeling of trust and the increased degree to which this project was seen as a collaborative space was reflected in the steady influx of artifacts that were entrusted to us for study, exhibition, and safekeeping for the duration of the project, as well as in the daily presence of women in the school. Besides the teaching process that was open to them, village women suddenly had a place to gather that they had a reason to be in; a social space which they could appropriate and coexist comfortably with men, without their presence being put in the question.

At the same time, the presence of men in the studio was one of the most surprising turns. Weaving is supposed to be an exclusively female activity, but many men who came to see the project eventually sat on the loom and reluctantly began to 
weave themselves. We gradually realized that the material presence of the loom, its imposing size, its repetitive whack, the small tasks entrusted to young boys (threading the spools for example), and the memories of their mothers and grandmothers working the loom, were deeply embedded in their earliest memories. The opening up of this space, the manifest physicality of the loom in work brought back memories that would not emerge otherwise. While young men entered the studio with a detached irony in the beginning, the sound of the working loom made them remember their childhood and close family members. Looms evoked affective aspects of memory that could only be performed, if reluctantly, and not communicated by words.

Re-enacting, rather than presenting the past, this studio brought to the fore affective states that had to do with a gender hierarchy of work and life in the village as well as the vicissitudes and pressures of mass production. These evocations of bodily memories served to demystify folkloric myths about the loom and its place in preindustrial rural societies. Dealing with these emergent aspects of an otherwise romanticized and "safe" folklore tradition showed how art can create situations that critically address issues left unencountered in a society. The fact that the very society in question took the opportunity to turn this studio into a space for this performativity to emerge created a series of unexpected issues, especially as it clashed with the perceived artistic integrity and freedom of the visual artist herself, as well as the expectations of the research team.

\section{A Question of Framing}

The main question, as well as the main point of friction between the many different parties involved in the working of this studio, was the framing of the project. Was it merely an ethnographic technique that subsumed artistic practice under a research methodology? Was it a purely artistic practice, in which the artist learned from locals but was then free to produce his or her work independently of community expectations? Was it a social space, where people involved, and especially nonexperts, would steer towards the direction that best served their immediate interests and concerns? Or was it one of those particular artworks that Joseph Beuys labeled social sculptures, with social engagement being a requirement for the work's completion? The opening up of engagement zones, as Onciul (2015) has shown, can be very complex, unpredictable and difficult to manage. The affective aspects of managing a space like that, in view of the conflictual demands and diverse backgrounds of participants are perhaps the most difficult to address and reflect upon retrospectively. However, the potential of ethnographic installations emphasizes precisely this difficult hybrid aspect as a corrective to the common positivity, political correctness, and self-praise that most community engagement projects adopt. 
Indeed, to open up a space to community participation means to have to address the unexpected and often frustrating demands of participants - demands that may be of a different nature to the initial planning and purpose of such an engagement. While this studio was aimed towards women, a group of local young men who share their time between the city of Heraklion and the village became regular supporters of the weaving studio in a variety of different ways, and at the same time appropriated the former abandoned school to serve their need for a place to host their gatherings during most evenings. A sense of ownership of the resources of the village and their entitlement to use them brought us into difficult situations, since we were entrusted with the keys to the school by the cultural association, and had to lock the doors to go home at night. Their insistence resulted in long hours at the school, and impromptu feasts that lasted until the early hours. Simultaneously, the mixing of young men in the village with young female students and staff from abroad was certainly not seen in an altogether positive light in the village. In Gonies, the gender ratio is strongly skewed towards men in ages below thirty, probably owing to the fact that young men are involved in several activities in the village related to herding, while women are left with almost nothing to do there. Therefore, initiating a primarily female-dominated activity in the weaving studio was much appreciated and warmly welcomed by younger men, but was seen as potentially problematic by older, more traditional inhabitants. The continuous presence of youths at the weaving studio, in any case, turned the school into a vibrant social space again, where feasts - the so-called parees - were held almost on a regular base.

The way the context of the weaving studio was formed was one of the unanticipated turns of the project. Having two distinct - yet often intertwined - functions made it almost impossible for Alexia to work on any artwork of her own. Her, and our, initial intention was to produce artworks that could later be exhibited on their own during fieldwork. But, given the demands of keeping a social space open and responding to the everyday situations that ensued, this was impossible. At the same time, women of the village wrested control of the produced artwork from the artist, and pushed it towards their own goals, conforming to their own aesthetic judgment and outlook. This is, we think, a common difficulty in art projects that engage with a community. To put it plainly, the choice is between creating an artwork that is communally produced but is not up to the artistic standards of the artist herself, or, on the other hand, letting the artist have the final word and produce something that corresponds to her work, but is in the end the product of a single person, albeit based on a research relationship with others.

Additionally, Alexia's characteristic humor and irony made her artistic intervention in the field a source of concern for our relationships with the people involved. Despite anthropology's appreciation of the plurality of approaches, putting the relationships 
between the anthropologists and the local community at risk by showing works that might be considered embarrassing or disparaging for the local community was resisted. Such a work was shown by the artist in a group show in Athens. The work was entitled "Adjacent to minced meat" and it was a series of covers from crossword puzzles where young semi-naked women are posing in front of the crossword itself. Alexia has painted over the female figures to give them the usual black dress of elderly widows in Greece, complete with black head-scarf. The title, which is a crossword question, was a critical take on masculine impressions of female sexuality, and the treatment of women by men in Crete.

As in other similar occasions, where anthropology appropriates methods and practices from contemporary arts and vice versa, bitterness was evoked on both sides (Schneider \& Wright, 2006). Tensions and differences were apparent throughout the course of the fieldwork. In retrospect, our main point of contention was that the research team tried to pull the frame back and look at this whole project as the artwork itself; to show that the performative aspect of the studio, as well as the engagement of locals into it, had enough "artistic" content to make it worthwhile. We understood in time that this is a deeply entrenched conflict, at least in the Greek art world. A presentation of the weaving project almost a year later among a closed group of artists and anthropologists led to some hostile reactions from the participating artists. Even though all the artists that participated in the discussion were practicing artistic research, employing practices and methods from anthropology and other social sciences, they fiercely criticised the weaving project for submitting contemporary art and even the artist herself to the uses demanded by anthropology and saw its purpose as merely utilitarian. Our purpose of producing ethnographic material through setting this ethnographic installation could not be, according to them, a shared goal between contemporary art and anthropology. According to this argument, artists are meant to produce artworks for exhibition and not ethnographic material for anthropologists to study and analyze. The debate revealed a lot about the complex relations between art and anthropology, at least in this national context.

Indeed, a simple artist-in-residence program would have provided the appropriate space and time for an artist to produce one or a series of artworks. It might even have provided Alexia with the opportunity to exhibit her work in a "proper" exhibition space and reach a much larger audience. Yet, the artist was invited to take part in the ethnographic fieldwork in Gonies, where there are limited facilities and even fewer opportunities to creatively work with the ethnographic material. Alexia soon abandoned the prospect of using her time to produce an artwork, and instead shared her studio with the ethnographic subjects and gathered a rich set of information and experiences for later consideration. Soon enough, after the end of this season's 
fieldwork, Alexia prepared a series of paintings that commented on her position in the field between the anthropologists and the Goniotes. The discussion was whether these paintings needed some sort of "curating," a juxtaposition with texts and other media to make them work as perspectives of our fieldwork. We were convinced very soon that these paintings could stand on their own for their artistic value and the novel perspectives they added to the field. These paintings were then exhibited in a solo show in a gallery in Heraklion so as the subjects of our ethnography had the chance to visit. However, the response of locals to these artworks was not as warm as the response to the open studio.

On the contrary, artistic practices applied in fieldwork through the weaving studio proved to be unexpectedly engaging for the local community and even attracted some foreign visitors to the village. The final presentation of the project kept an open, participatory form. We puzzled awhile on how to present and contextualize this effort. We resulted in taking a local musical motif, that has been sung in the village for at least a century, and write lyrics that described the studio in the local dialect. Katerina sang it as a concluding comment to the month-long studio. It was a comment on what actually happened, instead of a restating of goals and expectations.

More than a mere local community's consultation on planning and designing heritage experiences, the weaving studio involved locals in performing the past. Participants were encouraged to craft memories that would define the ways they understand and remember the past. Participation can take many different forms and levels and engagement can take even uncontrollable turns. Therefore it comes as no surprise that the weaving studio, although it was intended to be a participatory art studio, also became a vibrant social space for feasts and gatherings and a place where anthropologists had the chance to meet and work with locals. In the same vein, this alerts us to what local peoples and participating communities think about "art." While an artwork, especially in the contemporary sense of the term, can be seen as an interesting object, especially if it relates to the everyday life of the community, it potentially has the status of an alienated object, something that is "about" the community but not "of" it. This expands to an understanding of art in general, as an elite and detached mode of production that is irrelevant to the everyday needs of people.

Alexia had no previous fieldwork experience and for that reason, she did not adopt fieldwork techniques. Instead, she developed her own way of collecting ethnographic data according to her ethnographic-artistic thinking. In this way, the weaving studio focused more on the embodied memories of women that were narrated through performing and less on the verbal narratives about the past. However, this focus was aligned with the sensory turn in anthropology and also with the ethnographic 
turn in contemporary arts. From this viewpoint, the weaving project can be seen either as an art project or as ethnographic research and can be presented in both ways (Rutten, Dienderen, \& Soetaert, 2013). While the authors of this paper often present this endeavor as an art project within the ethnographic research, artist commentators have seen it, during various public presentations, as "merely" ethnographic research with some artistic interventions.

We see this project, however, as something even broader: we tried to pull away from the emphasis on the final product, on single or multiple artworks that would be the "outcome" of the studio. While we were not sure of the direction this whole endeavor would take, we thought this was part of the process itself. Inspired by work such as that of Joseph Beuys, who talked of "social sculpture," as well as the more recent approaches by Rick Lowe, we identified these approaches as akin to the recent turn in anthropology towards co-produced knowledge that is not outcome-oriented but processoriented. We felt the need to break free from the tyranny of deliverables and focus more on the processes that produced them. We felt that this tyranny was a common feature of both the visual arts, where the artist has to produce a portfolio of works to advance and in the social sciences, where the final products (almost exclusively published texts in high-impact journals) are more important than community work in the context of an audit culture in the late capitalist university. The opening up of a space where crafts production could create a meeting ground for scholars, artists, and locals. 


\section{Acknowledgements}

The weaving project was supported by the Heritage Management Organisation. We thank Dr. Evangelos Kyriakidis for giving us the opportunity to make this project happen. We are also grateful to DA art space in Heraklion that hosted the exhibition of Alexia Karavela, and Elli Froudaraki for her understanding and her helpful advice. We also thank the members of the project, Lena Stefanou and Celine Murphy, for their support and engagement in the field. Last, but not least, we need to express our gratitude to the people of Gonies, and especially the women who took this project up and made it into a rich and unforgettable experience. 


\section{REFERENCES}

Barone, T., \& Eisner, E. W. (2012). Arts based research. Los Angeles, CA: SAGE.

Black, G. (2005). The engaging museum: Developing museums for visitor involvement. New York, NY: Routledge.

Castañeda, Q. E. (2009). The "past" as transcultural space: Using ethnographic installation in the study of archaeology. Public Archaeology, 8(2-3), 262-282. http://doi.org/10.1179/175355309X457277

Coy, M. W. (1989). Apprenticeship: From theory to method and back again. New York, NY: State University of New York Press.

Culhane, D., \& Denielle E. (Eds.). (2017). "A different kind of ethnography: Imaginative practices and creative methodologies." North York, ON: University of Toronto Press.

Downey, G., Dalidowicz, M., \& Mason, P. H. (2015). Apprenticeship as method: Embodied learning in ethnographic practice. Qualitative Research, 15(2), 183-200. http://doi.org/10.1177/1468794114543400

Grimshaw, A., \& Ravetz, A. (Eds.). (2005). Visualizing anthropology: Experimenting with image-based ethnography. Bristol, UK: Intellect.

Herzfeld, M. (1985). The poetics of manhood: Contest and identity in a cretan mountain village. New Jersey, NY: Princeton University Press.

Herzfeld, M. (1987). Anthropology through the looking-glass: Critical ethnography in the margins of Europe. Cambridge, UK: Cambridge University Press.

Kyriakidis, E., \& Anagnostopoulos, A. (forthcoming, 2019). Decision making in archaeological heritage: Prospects and limitations of enhancing democracy through a community archaeology project in Crete. Journal of Community Archaeology and Heritage.

Kyriakidis, E., \& Anagnostopoulos, A. (2015). Archaeological ethnography, heritage management, and community archaeology: A pragmatic approach from Crete. Public Archaeology, 14(4), 240-262. http://doi.org/ $\underline{10.1080 / 14655187.2016 .1221988}$ 
Kyriakidis, E., \& Anagnostopoulos, A. (2017). Engaging local communities in heritage decision-making: The case of Gonies, Crete, Greece. Journal of Eastern Mediterranean Archaeology \& Heritage Studies, 5(3-4), 334. http://doi.org/ 10.5325/jeasmedarcherstu.5.3-4.0334

Laine, A. (2018). Practicing art and anthropology : A transdisciplinary journey. London, UK: Bloomsbury Academic

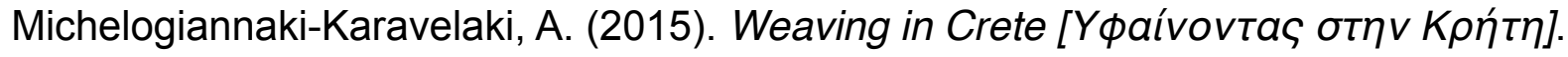
Heraklion, GR: Itanos.

Onciul, B. (2015). Museums, heritage and indigenous voice: Decolonizing engagement. New York, NY: Routledge.

Pink, S. (2005). Doing visual ethnography. London, UK: SAGE.

Rutten, K., Dienderen, A. Van, \& Soetaert, R. (2013). Revisiting the ethnographic turn in contemporary art. Critical Arts South-North Cultural and Media Studies, 27(5), 459-473. http://doi.org/10.1080/02560046.2013.855513

Salazar, N. B. (2012). Tourism imaginaries: A conceptual approach. Annals of Tourism Research, 39(2), 863-882. http://doi.org/10.1016/j.annals.2011.10.004

Sansi, R. (2015). Art, anthropology and the gift. London, UK: Bloomsbury Academic. http://doi.org/10.5040/9781474214087

Schneider, A., \& Wright, C. (Eds.) (2006). Contemporary art and anthropology. New York, NY: Berg.

Schneider, A., \& Wright, C. (Eds.) (2010). Between art and anthropology: Contemporary ethnographic practice. London, UK: Berg Publishers.

Schneider, A., \& Wright, C. (Eds.) (2013). Anthropology and art practice. London, UK: Bloomsbury Academic.

Stefanou, E., Anagnostopoulos, A., \& Kyriakidis, V. (2017). Community engagement through archaeological ethnography: Learning in situ with a field school in Gonies Maleviziou, Crete. AP: Online Journal in Public Archaeology, 7(0), 85. http:// doi.org/10.23914/ap.v7i0.180 
Wang, Q., Coemans, S., Siegesmund, R., \& Hannes, K. (2017). Arts-based methods in socially engaged research practice: A classification framework. Art/Research International: A Transdisciplinary Journal, 2(2), 5. http://dx.doi.org/10.18432/ $\underline{\text { R26G8P }}$

Zorn, E. (2004). Weaving a future: Tourism, cloth, and culture on an Andean Island. lowa, IA: University of lowa Press. 


\section{ENDNOTES}

1 Sewing motifs with thread on the fabric as it is weaved on the loom.

2 A census taken by the Office of Regional Development of the Ministry of Coordination in 1959 recorded 152 functional looms in the village. A quick calculation indicates that there was one loom for every two families engaged in mass production. (Archive of the Regional Development Service, Ministry of Coordination - General Archives of State, Heraklion, Crete).

${ }^{3}$ More on Alexia Karavela's work can be found at https://alekakaravela.blogspot.com/ 